\title{
Past selection explains differentiation in flowering phenology of nearby populations of a common alpine plant
}

\author{
Halil Kesselring ${ }^{1}$ - Georg F. J. Armbruster ${ }^{1}$ - Elena Hamann ${ }^{1}$ · Jürg Stöcklin ${ }^{1}$
}

Received: 5 May 2015/Accepted: 4 September 2015/Published online: 14 September 2015

(C) Swiss Botanical Society 2015

\begin{abstract}
The timing of and relative investment in reproductive events are crucial fitness determinants for alpine plants, which have limited opportunities for reproduction in the cold and short growing seasons at high elevations. We use the alpine Anthyllis vulneraria to study whether flowering phenology and reproductive allocation have been under diversifying selection, and to assess genetic diversity and plastic responses to drought in these traits. Open-pollinated maternal families from three populations in each of two regions from the Swiss Alps with contrasting precipitation were grown in low and high soil moisture in a common garden. We measured onset, peak, and end of flowering, as well as vegetative and reproductive aboveground biomass. Population differentiation for each character $\left(Q_{\mathrm{ST}}\right)$ was compared to differentiation at neutral microsatellite loci $\left(F_{\mathrm{ST}}\right)$ to test for past selection. We found population differentiation in onset and peak of flowering which results from natural selection according to $Q_{\mathrm{ST}}-F_{\mathrm{ST}}$. End of flowering and biomass were not significantly differentiated among populations. Reduced soil moisture had no consistent effect on mean onset of flowering, and advanced peak and end of flowering by less than 1 week. Reproductive biomass was strongly decreased by lowered soil moisture. No genetic variation within or among populations was found for plasticity in any trait
\end{abstract}

Electronic supplementary material The online version of this article (doi:10.1007/s00035-015-0157-z) contains supplementary material, which is available to authorized users.

Halil Kesselring

halil.kesselring@unibas.ch

1 Department of Environmental Sciences, Section Plant Ecology, University of Basel, Schönbeinstrasse 6, 4056 Basel, Switzerland measured. The results suggest past heterogeneous selection on onset and peak of flowering in alpine Anthyllis vulneraria and potentially indicate local adaptation to differences in snowmelt date over distances $<5 \mathrm{~km}$. Limited variation in plastic responses to reduced soil moisture suggests that soil moisture might not vary between populations.

Keywords Local adaptation $\cdot Q_{\mathrm{ST}}-F_{\mathrm{ST}}$ comparison . Phenotypic plasticity · Drought

\section{Introduction}

Evolution by means of divergent natural selection in spatially heterogeneous environments is considered the major cause of phenotypic variation (Linhart and Grant 1996; Schluter 2009). Apart from divergent natural selection, phenotypic variation among populations can also result from genetic drift-random variation in allele frequencies eventually resulting in the fixation of alleles in some populations and their extinction in other populations (Wright 1931). Furthermore, population differentiation may result from the expression of different phenotypes by the same genotypes in different environments, a phenomenon referred to as phenotypic plasticity (Bradshaw 1965). In alpine plants, both local adaptation and phenotypic plasticity have been hypothesized particularly important due to the steep environmental gradients across short geographical distances. On the other hand, populations of alpine plants are frequently small owing to the highly structured landscape, thereby intensifying genetic drift. The relative significance of genetic drift, local adaptation, and plasticity for population differentiation in alpine environments, however, is a question that remains insufficiently answered (Leimu and Fischer 2008; Frei et al. 2014). 
The timing of reproductive events and the allocation of resources to reproduction are particularly crucial fitness determinants in the highly seasonal alpine environments (Rathcke and Lacey 1985; Ozenda 1985; Körner 2003). As temperature decreases along rising elevation with $0.55{ }^{\circ} \mathrm{C} /$ $100 \mathrm{~m}$, the snow-free period and the time window for reproduction narrow down (Schroeter 1923). At high elevations, flowering phenology is therefore tightly linked to the date of snowmelt (Hülber et al. 2006). Among animalpollinated plant species, the phenology and allocation of reproductive effort must also be coordinated with pollinator abundances and behaviour (Müller 1881; Kudo 1996). Temperature and the date of snowmelt at high elevations are subject to strong microhabitat effects, which may outweigh elevational effects of a few hundred metres (Scherrer and Körner 2010; Wheeler et al. 2014). Therefore, the tight links of temperature and snowmelt with phenology and pollinator behaviour (Bergman et al. 1996) are expected to result in strong population differentiation in flowering phenology. The sensitivity of flowering phenology to external conditions can further facilitate reproductive isolation via asynchronous flowering time and therefore promote differentiation and local adaptation (Linhart and Grant 1996; Hall and Willis 2006; Hülber et al. 2010).

Contrarily, the evolution of phenotypic plasticity is expected when genotypes or lineages are likely to experience various external conditions due to high spatial or temporal environmental heterogeneity (Sultan and Spencer 2002). Flowering phenology is an inherently plastic trait that is strongly environmentally controlled through temperature, photoperiod, or both (Keller and Körner 2003). Phenotypic plasticity can slow the response to selection when genetic variation in plasticity exists in a population, i.e. when all genotypes in the population do not respond to environmental change in the same way. Natural selection then cannot operate on trait means as efficiently as when environments and phenotypes are stable, because the same genotype does not have highest fitness under all conditions (Via and Lande 1985). The question, whether mean flowering time is subject to divergent selection among populations in the highly variable alpine landscape remains rarely addressed (Scheepens et al. 2011; Scheepens and Stöcklin 2013; Frei et al. 2014).

Besides temperature and photoperiod, reproductive characters such as reproductive allocation are likely to respond to soil water availability (Caruso 2006, and references therein), because flowering incurs substantial water costs to the plant. The transpirational water loss of flowers can exceed that of leaves (Galen et al. 1999; Lambrecht 2013). Alpine plants often have big flowers relative to the vegetative body (Körner 2003). Disproportionately large flowers therefore might further raise water costs. Under drought, plants produce smaller flowers and smaller reproductive structures in general (Mal and Lovett-Doust 2005; Caruso 2006), and were also found to advance flowering phenology as a plastic as well as an evolutionary response (Dunne et al. 2003; Franks 2011). Precipitation is very variable across the European Alps as a result of the interplay of climatic patterns with the obstructing effect of mountain ranges. This leads to regions of particularly low precipitation in the deep valleys inside the highest mountain ranges (Ozenda 1985).

Here we use comparisons of quantitative trait differentiation and genetic differentiation at neutral marker loci $\left(Q_{\mathrm{ST}}-\right.$ $F_{\text {ST }}$ comparisons; Spitze 1993) to test for the role of past selection in shaping patterns of population differentiation in reproductive allocation and phenology in a common alpine herb. $Q_{\mathrm{ST}}-F_{\mathrm{ST}}$ comparisons allow to infer natural selection as opposed to random processes such as genetic drift as a cause of population differentiation when $Q_{\mathrm{ST}}$ is either significantly smaller or larger than $F_{\mathrm{ST}} \cdot Q_{\mathrm{ST}}$ values smaller than $F_{\text {ST }}$ values indicate stabilizing selection across environments, whereas $Q_{\mathrm{ST}}$ 's larger than $F_{\mathrm{ST}}$ indicate population divergence as a result of heterogeneous selection across environments. If $Q_{\mathrm{ST}}=F_{\mathrm{ST}}$, we have no reason to infer a role of selection as drift alone can explain the observed population differentiation. We also assess plastic responses to drought in reproductive allocation and phenology by subjecting plants to two soil moisture treatments in a common garden. We asked (1) if population differentiation in reproductive allocation and flowering phenology is likely the result of past selection and therefore adaptive evolution, and (2) if soil moisture availability has an effect on reproductive allocation and phenology (i.e. presence of phenotypic plasticity).

\section{Methods}

\section{Study species}

Anthyllis vulneraria L. sensu lato (s.1.) is a polymorphic fabaceae taxon with unclear infraspecific classification (Nanni et al. 2004; Köster et al. 2008), and consists of a selfcompatible clade of short-lived herbaceous plant species very common throughout Europe. It grows preferably on calcareous meadows and scree slopes from sea level to the alpine belt up to around $3000 \mathrm{~m}$ a.s.l. (Hegi 1975). Here, we examined three alpine populations of Anthyllis vulneraria in each of two regions in the Swiss Alps. Plants grow to a height of around $15-45 \mathrm{~cm}$. A variable number of shoots sprout from the basal leaf rosette, each bearing 2-6 inflorescences. Each inflorescence comprises a number of 7-19 mm long white to yellow, sometimes claret to red flowers arranged in a capitulum (Hegi 1975; Navarro 1999). Shoots are usually unbranched, but may have up to three side 
branches originating from the axils of evenly pinnate compound leafs. Leafs of the basal rosette consist of the enlarged terminal leaflet of a compound leaf. Anthyllis vulneraria is representative of a type of fabaceae flower characterized by a pump mechanism adapted to insect-mediated pollination (Müller 1881). Flower development of Anthyllis vulneraria takes approximately 4 weeks. Flowers ripen from bottom to top along a shoot and from top to bottom within a capitulum. Asynchronous flower ripening allows for geitonogamous selfing across capitulae, but suggests multiple paternity per maternal offspring. Microsatellite analyses found a variable degree of inbreeding in the studied populations ( $F_{\text {IS }} 0-0.42$, unpublished results), suggesting regular outcrossing. A single flower is open and accessible to pollinators for about 6-7 days and produces a single seed.

\section{Experimental procedures}

In August 2012, seeds from open-pollinated wild flowers in three populations from each of two regions (eastern and western Swiss Alps near Davos and Zermatt, respectively) were sampled (Table 1; Online Resource 1). The offspring of the same maternal plant are referred to throughout the article as seed family. Members of a seed family presumably are mostly half-sibs, as populations are outcrossed, and the asynchronous ripening of flowers within a capitulum makes it unlikely that they are sired by the same father (Pannell and Labouche 2013). Populations are situated between 2000 and $2650 \mathrm{~m}$ a.s.l. Distances between populations within regions range from 2 to $18 \mathrm{~km}$, and regions are $180 \mathrm{~km}$ apart. Regions were specifically chosen for their difference in growing season precipitation, with the Davos region getting approximately $50 \%$ more precipitation in the months of June through September than the Zermatt region (Table 1; Zimmermann and Kienast 1999). A clear assignment of every population to one of the numerous subspecies of $A n$ thyllis vulneraria is difficult (Hegi 1975). We have assigned four of our populations to Anthyllis vulneraria ssp. alpestris (Schult.) Asch. and Graben, and two to Anthyllis vulneraria ssp. valesiaca (Beck) Guyot (Lauber et al. 2012). Seeds were stored in the refrigerator until they were scarified and sown in early August 2013 directly into their final high mineral potting soil mixture $\left(210 \mathrm{~L}\right.$ Ökohum Anzuchterde ${ }^{\circledR}$ with $14 \mathrm{~L}$ sand and $8 \mathrm{~kg}$ pumice). Five individuals per seed family, and six seed families per population were used (180 individuals in total). Seedlings were kept in the greenhouse in 10 by $10 \mathrm{~cm}$ pots and watered ad libitum. Plants were randomized twice per week. Greenhouse heating and cooling systems were set so that temperatures would not fall below 16 and $8{ }^{\circ} \mathrm{C}$ at day and night, respectively, nor exceed 20 and $10^{\circ} \mathrm{C}$ at day and night, respectively. Early leaf size was measured on every individual as length $\times$ width $/ 2$ of the first true leaf as soon as it was fully developed (two-leaf stage). After 4.5 weeks, on 11 September 2013, seedlings were potted into larger $2 \mathrm{~L}$ pots into the same soil mixture and watered to carrying capacity. At the same time, plants were moved to the outside garden under a UV-B transmissible rain shelter (folitec Agrarfolien-Vertriebs $\mathrm{GmbH}$, Westerburg, Germany) and arranged in a regular array, alternating between individuals of all levels of hierarchy from seed family to region. Eleven days later, on the 22 September 2013, treatment began by watering plants designated for the wet treatment. Alternating between seed families, three or two of the five individuals per seed family were allocated to the dry treatment. Subsequently, volumetric soil moisture content was monitored with a moisture metre calibrated to the soil mixture used in the experiment and plants were watered accordingly $(\mathrm{HH} 2$ Moisture Meter with Theta Probe ML2x, Delta-T Devices Ltd. Cambridge, England). Wet plants were watered when mean soil moisture fell below $18 \%$, and dry plants when soil moisture fell below $5 \%$. Ten different plants of each treatment were randomly chosen each time at irregular intervals for soil moisture measurements (Online Resource 2). Plants were sitting on a thick sand bed and marginally struck roots into the sand $2 \mathrm{~cm}$ deep at maximum. Throughout the duration of the experiment, air temperature was logged hourly with a TidbiT $^{\circledR}$ v2 Temperature Logger (Onset Computer

Table 1 Coordinates (Swiss coordinate system LV03), elevation, and mean monthly precipitation during the growing season (June-September) of the six populations of Anthyllis vulneraria studied in the common garden

\begin{tabular}{lllll}
\hline Region & Population & Coordinates $\left({ }^{\circ} \mathrm{E} /{ }^{\circ} \mathrm{N}\right)$ & $\begin{array}{l}\text { Elevation } \\
(\mathrm{m} \text { a.s.1.) }\end{array}$ & $\begin{array}{l}\text { Summer precipitation } \\
(\mathrm{mm})\end{array}$ \\
\hline Davos & Schiahorn & $780513.385 / 187874.756$ & 2650 & 1463 \\
& Casanna & $782301.543 / 192247.969$ & 2320 & 1454 \\
& Monstein & $779685.630 / 173389.160$ & 2010 & 1225 \\
Zermatt & Findelwald & $626828.986 / 95475.764$ & 2170 & 809 \\
& Findelgletscher & $629173.611 / 95175.270$ & 2490 & 939 \\
& Stafelalp & $619094.320 / 94427.436$ & 2280 & 898 \\
\hline
\end{tabular}

Precipitation data are interpolated from monthly precipitation data using a digital elevation model (Zimmermann and Kienast 1999) 
Corporation, Bourne, MA, USA; Online Resource 3). The logger was hung-up under a reversed $2 \mathrm{~L}$ plastic flowerpot painted in white and with perforation to allow air circulation. All plants were preventively treated with a ready-to-use fungicide powder (Maag Pirox ${ }^{\circledR}$, Syngenta Agro AG, Dielsdorf, Switzerland) on a few occasions during growth phase, because alpine Anthyllis vulneraria is susceptible to mildew when grown at low elevations. Anthyllis vulneraria needs vernalisation to induce flowering (Halil Kesselring, personal observation), so we left plants outside over winter. During winter, from 19 November 2013 onwards, the rain shelter was temporarily removed and water treatment was suspended. Treatment was re-established on the 19 March 2014 by watering with 100 and $60 \mathrm{~mL}$ for wet and dry plants, respectively, and subsequently continued as described above.

Once reproductive shoots became visible, plants were checked daily and the dates of the following critical stages of flowering phenology were noted for each individual: (1) onset of flowering defined as the date when the first flower opened on an individual; (2) peak of flowering defined as the date at which the maximum number of open flowers was observed; (3) end of flowering defined as the date when the last flower opened and no more flower buds were visible. Flower opening is very easily observed in Anthyllis vulneraria when the brightly coloured corolla appears from the calyx, a process that takes less than $24 \mathrm{~h}$. Onset of flowering was always a representative measure because the opening of the first flower was never an isolated event, but led to the onset of flowering of the whole plant.

Once a plant had reached the flower end, aboveground biomass was harvested and dried at $75{ }^{\circ} \mathrm{C}$ for $72 \mathrm{~h}$. Aboveground biomass was then separated into the vegetative leaf rosette and into reproductive parts, and weighed to the nearest $\mathrm{mg}$. We also estimated reproductive allocation as the ratio of reproductive biomass over total aboveground biomass.

\section{Statistical analyses}

We performed separate linear mixed-effects models for each of our flowering phenology variables and for the biomass variables in $\mathrm{R}$ version 3.0.2 ( $\mathrm{R}$ Development Core Team 2008). In these models, water treatment and region as well as their interaction were included as fixed effects, and population and seed family and their interactions with water treatment were included as random terms. Each seed family was given a unique identifier, which leads to the models implicitly nesting seed family in population. Likewise, population was nested in region. In these models, a significant water treatment effect indicates that soil moisture availability has an effect on either flowering phenology or aboveground biomass allocation, i.e. the focal trait is plastic in response to soil moisture. A significant interaction between water treatment and region indicates that populations from both regions differ in their plastic responses to soil water availability. Analogously, a significant seed family effect indicates that related individuals are more similar to each other in the focal trait expression than randomly grouped individuals, and an interaction of seed family with water treatment indicates genetic variation in phenotypic plasticity among seed families within populations. To control for maternal effects to the maximum possible extent, early leaf size (length $\times$ width/2) was included in all models as covariate. Statistical models were computed with the lmerTest package (Kuznetsova et al. 2013). lmerTest applies $F$ tests to lmer objects of the lme4 package for fixed effects and likelihood-ratio tests for random effects using stepwise model reduction and comparisons. We used type 3 errors and Satterthwaite approximations for denominator degrees of freedom. We report $P$ values, mean squares, and Chi-square values that correspond to those from the model comparisons using the step function in lmerTest (i.e. likelihood-ratio tests). All random terms were specified as simple scalar terms. Phenological variables were analysed as date objects. Contrasts for fixed effects were tested using differences of least squares means as implemented in the step function of lmerTest.

\section{Molecular analyses}

Twenty individuals per population were scored for amplified fragments at nine microsatellite loci. We used Spreadex ${ }^{\circledR}$ gels and the ORIGINS electrophoresis unit (Elchrom Scientific AG, Cham, Switzerland) to separate PCR amplicons with size differences as small as $2 \mathrm{bp}$. Gels were stained with ethidium-bromide and scored by hand comparing against the M3 ladder from ELCHROM. Polymorphic microsatellites were developed to be suitable in length for analysis on Spreadex ${ }^{\circledR}$ gels (Kesselring et al. 2013). PCR programs were run in a Mastercycler Gradient (Eppendorf, Hamburg, Germany). 35 cycles with denaturation for $30 \mathrm{~s}$ at $95{ }^{\circ} \mathrm{C}$, start PCR for $30 \mathrm{~s}$ at $95{ }^{\circ} \mathrm{C}$, locus-specific annealing temperature $\left(50\right.$ or $\left.52{ }^{\circ} \mathrm{C}\right)$ for $45 \mathrm{~s}$, followed by $45 \mathrm{~s}$ at $72{ }^{\circ} \mathrm{C}$ were repeated. Termination was set to $72{ }^{\circ} \mathrm{C}$ for $8 \mathrm{~min}$. A detailed description of the microsatellite development and loci description can be found in Kesselring et al. (2013). The free software FreeNA (Chapuis and Estoup 2007) was used to check for null alleles. Null alleles were suggested for several loci, but taking their frequencies into account resulted in nearly identical $F_{\mathrm{ST}}$ estimates for each locus except locus 8. Mean $F_{\mathrm{ST}}$ was slightly lower with null alleles taken into account, therefore inclusion of null alleles would render tests of $Q_{\mathrm{ST}}>F_{\mathrm{ST}}$ less conservative. Since a low degree of inbreeding is suggested by the data and the floral biology of Anthyllis vulneraria, and since blank lanes 
(homozygote null alleles) were only present at locus 8 , we are confident that increased homozygosity at all but one locus is not due to null alleles, but results from bi-parental inbreeding and selfing. Estimation of null alleles rests on untested assumptions (e.g. a single null allele is present) and is not free of bias (Chapuis and Estoup 2007; David et al. 2007). Consequently, we preferred to remove the outlier locus with clear signals of null alleles instead of including null allele frequencies for final analyses. Genotyping error was estimated at $2.5 \%$ (Kesselring et al. 2013). Population pairwise $F_{\text {ST }}$ values were calculated in GenAlEx (Peakall and Smouse 2006) based on allele frequencies. Probabilities of finding the observed $F_{\text {ST }}$ values are based on comparison of the observed value against 999 random permutations of the samples.

\section{$Q_{\mathrm{ST}}-F_{\mathrm{ST}}$ comparison}

$Q_{\mathrm{ST}}-F_{\mathrm{ST}}$ comparisons were performed for all traits to test whether population differentiation in quantitative traits is the result of natural selection. We followed the method described by Whitlock and Guillaume (2009), which provides a powerful significance test of the hypothesis that $Q_{\mathrm{ST}}$ is not equal to $F_{\mathrm{ST}}$. For each trait, a null distribution of $Q_{\mathrm{ST}}-$ $F_{\text {ST }}$ is first constructed based on the observed within-population genetic variance for the focal trait and observed $F_{\mathrm{ST}}$. Since it is based on the $F_{\mathrm{ST}}$, this null distribution is the expected distribution of $Q_{\mathrm{ST}}-F_{\mathrm{ST}}$ under neutral evolution of the trait. The tail probability of the observed $Q_{\mathrm{ST}}-F_{\mathrm{ST}}$ under the assumption of neutral evolution is then calculated from the null distribution.

The software Nemo version 2.2.0 (Guillaume and Rougemont 2006) was used to calculate Weir and Cockerham's coefficients a, b, and c for each of the 8 microsatellite loci as a basis to estimate Wright's $F_{\mathrm{ST}}$ (Weir and Cockerham 1984). Whitlock and Guillaume (2009) provide an $\mathrm{R}$ script for a nonparametric bootstrap of $F_{\mathrm{ST}}$ values, which was used to generate $10^{3}$ bootstrap replicates of $F_{\mathrm{ST}}$, from which a probability distribution of $F_{\text {ST }}$ was constructed. The script calculates $F_{\mathrm{ST}}$ 's by randomly sampling with replacement from the Weir and Cockerham coefficients calculated by Nemo a number of times equivalent to the number of loci used in the analyses. The $\mathrm{Q}_{\mathrm{ST}}$ replicates were calculated by parametric bootstrapping using the Lewontin-Krakauer distribution and the observed within-population variances and observed $\mathrm{F}_{\mathrm{ST}}$ according to Whitlock and Guillaume (2009). For the calculation of Q QST's, we used Spitze's (1993) formula, estimating within-population variances as 4 times the seed family variance components, and among-population variance as the population variance components from the statistical models. Some degree of inbreeding is indicated in 5 of the studied populations by heterozygote deficiencies. Therefore, the assumption of half-sibs may not always hold, and render tests of $\mathrm{Q}_{\mathrm{ST}}>\mathrm{F}_{\mathrm{ST}}$ too conservative and those of $\mathrm{Q}_{\mathrm{ST}}<\mathrm{F}_{\mathrm{ST}}$ too relaxed. We have therefore repeated the analyses under the assumption of full-sibs which is the opposite extreme. Results were identical, except that significant results were even more strongly significant under the assumption of full-sibs. We only report results assuming half-sibs as this is the more realistic and more conservative assumption. We used the minimal adequate models resulting from stepwise model reduction as implemented in the step function of lmerTest for estimation of all variance components used in the $\mathrm{Q}_{\mathrm{ST}}-\mathrm{F}_{\mathrm{ST}}$ comparisons. The entire sample across both treatments was used for analyses to achieve reasonable sample sizes. If the minimal model did not include population or seed family those terms were reincluded as they are necessary for calculations of $Q_{\mathrm{ST}}$.

\section{Results}

In the experimental garden, global mean peak flowering was on the 25 April 2014. Peak flowering in the natural stands of these populations is roughly in the last week of June (Halil Kesselring, personal observation). Therefore, plants in this experiment flowered approximately 2 months earlier than the natural stands, equalling a $1 \mathrm{~h} 45$ min shorter photoperiod. All populations were significantly differentiated at microsatellite loci from one another [average $F_{\mathrm{ST}}=0.079$, $95 \%$ CI $(0.063,0.098)]$ except populations Stafelalp and Findelwald (Table 2). Mean pairwise population differentiation within regions $\left(F_{\mathrm{ST}}=0.04\right)$ was lower than mean pairwise population differentiation across regions $\left(F_{\text {ST }}=0.08\right.$, Table 2$)$.

\section{Effects of origin on allocation of biomass and phenology}

Differentiation at the regional level was only indicated for vegetative biomass and reproductive allocation (ratio of reproductive biomass over total aboveground biomass), but not for reproductive biomass by statistical analyses (Table 3). Populations nested within region were not significantly differentiated for biomass traits (Table 3), with observed $Q_{\mathrm{ST}}$ 's of 0.074 and 0.11 for vegetative and reproductive biomass, respectively. Accordingly, observed $Q_{\mathrm{ST}}-$ $F_{\text {ST }}$ values fell within the $95 \%$ confidence limit of the corresponding null distributions for both vegetative $(P=0.666)$ and reproductive biomass $(P=0.429)$, giving no reason to infer selection as a driver of population evolution. Variance components analysis of the random terms revealed that large amounts of variability in vegetative and reproductive aboveground biomass were explained by seed family (31 and $22 \%$, respectively; Table 3), indicating high within-population genetic diversity. 
Table 2 Population pairwise $\mathrm{F}_{\mathrm{ST}}$ values (below diagonal) with tail probabilities based on 999 random permutations of samples as implemented in GenAlEx given (above diagonal)

\begin{tabular}{llllllr}
\hline & Schiahorn & Casanna & Monstein & Findelgletscher & Findelwald & Stafelalp \\
\hline Davos & & & & & 0.001 \\
$\quad$ Schiahorn & - & 0.001 & 0.001 & 0.001 & 0.001 & 0.001 \\
Casanna & 0.051 & - & 0.037 & 0.001 & 0.001 & 0.001 \\
$\quad$ Monstein & 0.084 & 0.014 & - & 0.001 & 0.014 \\
Zermatt & & & & - & - & 0.001 \\
Findelgletscher & 0.127 & 0.078 & 0.096 & 0.02 & 0.000 \\
Findelwald & 0.095 & 0.038 & 0.064 & 0.052 & - \\
Stafelalp & 0.098 & 0.039 & 0.085 & & & 0.000 \\
\hline
\end{tabular}

Table 3 The effects of population origin, soil moisture treatment, and family membership on aboveground biomass and reproductive phenology (linear mixed-effects analyses)

\begin{tabular}{|c|c|c|c|c|c|c|c|c|c|c|c|c|c|c|c|c|c|c|}
\hline \multirow[t]{2}{*}{ Factor } & \multicolumn{3}{|c|}{$\begin{array}{l}\text { Vegetative } \\
\text { biomass }\end{array}$} & \multicolumn{3}{|c|}{$\begin{array}{l}\text { Reproductive } \\
\text { biomass }\end{array}$} & \multicolumn{3}{|c|}{$\begin{array}{l}\text { Reproductive } \\
\text { allocation }\end{array}$} & \multicolumn{3}{|c|}{$\begin{array}{l}\text { Onset of } \\
\text { flowering }\end{array}$} & \multicolumn{3}{|c|}{$\begin{array}{l}\text { Peak of } \\
\text { flowering }\end{array}$} & \multicolumn{3}{|c|}{$\begin{array}{l}\text { End of } \\
\text { flowering }\end{array}$} \\
\hline & $d f$ & $\mathrm{~F} / \chi^{2}$ & $P$ & $d f$ & $\mathrm{~F} / \chi^{2}$ & $P$ & $d f$ & $\mathrm{~F} / \chi^{2}$ & $P$ & $d f$ & $\mathrm{~F} / \chi^{2}$ & $P$ & $d f$ & $\mathrm{~F} / \chi^{2}$ & $P$ & $d f$ & $\mathrm{~F} / \chi^{2}$ & $P$ \\
\hline Early leaf size & 1 & 15.40 & $* *$ & & 23.35 & $* *$ & 1 & 10.33 & $*$ & 1 & 0.02 & NS & 1 & 1.29 & NS & 1 & 0.71 & NS \\
\hline Region & 1 & 15.77 & $* *$ & 1 & 26.17 & NS & 1 & 12.30 & $*$ & 1 & 8.40 & $* *$ & 1 & 8.54 & $*$ & 1 & 7.79 & $* * *$ \\
\hline Treatment & 1 & 5.40 & $*$ & 1 & 27.06 & $* * *$ & 1 & 31.26 & $* * *$ & 1 & 0.09 & NS & 1 & 4.36 & $*$ & 1 & 12.20 & $* * *$ \\
\hline Region $\times$ treatment & 1 & 4.74 & $*$ & 1 & 3.34 & $*$ & 1 & 8.44 & $*$ & 1 & 0.24 & NS & 1 & 0.03 & NS & 1 & 0.27 & NS \\
\hline Population (region) & NA & 1.94 & NS & NA & 1.60 & NS & NA & 0 & NS & NA & 17.51 & $* *$ & NA & 21.37 & $* * *$ & NA & 0.88 & NS \\
\hline Seed family (population) & NA & 32.91 & $* * *$ & NA & 24.98 & $* * *$ & NA & 14.54 & $* * *$ & NA & 8.58 & $* *$ & NA & 12.35 & $* *$ & NA & 23.18 & $* * *$ \\
\hline Population $\times$ treatment & NA & 0 & NS & NA & 0.03 & NS & NA & 0 & NS & NA & 0 & NS & NA & 0.29 & NS & NA & 0 & NS \\
\hline Seed Family $\times$ treatment & NA & 0 & NS & NA & 1.14 & NS & NA & 0 & NS & NA & 0 & NS & NA & 0 & NS & NA & 0 & NS \\
\hline
\end{tabular}

Early leaf size (measured as length $\times$ width $/ 2$ of the first fully developed true leaf) was included as a covariate to control for maternal effects. $* * * P<0.001$, ** $P<0.01, * P<0.05, N S$ not significant. F ratios are given for fixed effects and $\chi^{2}$ values for random effects. Reproductive allocation is the ratio of reproductive biomass over total aboveground biomass

The two regions were significantly differentiated for all stages of reproductive phenology (Table 3). All populations from Zermatt flowered later than any of the populations from Davos, and the difference in peak flowering date between the first population from Davos and the last one from Zermatt was more than 5 weeks (Fig. 1). Significant population differentiation within regions was indicated by the statistical models for onset and peak of flowering, but not for end of flowering (Fig. 1; Table 3). Observed $Q_{\mathrm{ST}}$ 's ranged from 0.020 for end of flowering to 0.353 for peak flowering (Fig. 2). The observed $Q_{\mathrm{ST}}-F_{\mathrm{ST}}$ value for end of flowering fell within the $95 \%$ confidence limit of the corresponding null distribution $(P=0.984)$, and therefore differentiation in this trait can be explained by drift alone. $Q_{\mathrm{ST}}-F_{\mathrm{ST}}$ values for onset and peak of flowering were greater than expected under the null hypothesis and appeared in the tail of the corresponding null distributions with an associated probability of finding the observed value or one that is greater of 0.002 and 0.001 , respectively. Therefore, divergent selection is indicated for onset and peak of flowering. The observed $F_{\mathrm{ST}}$ as inferred from the microsatellite data was 0.079 [95\% CI $(0.063,0.098)]$ averaged over all loci. Genetic variation within populations was indicated for all phenological variables by significant seed family terms (Table 3). Seed family explained 10,11 , and $37 \%$, of the variability in the random terms for onset, peak, and end of flowering, respectively.

\section{Effects of treatment on biomass allocation and reproductive phenology}

Regions responded differently in their aboveground biomass to the soil moisture treatment (significant region $x$ treatment for vegetative and reproductive biomass, and reproductive allocation; Table 3). Contrasts of the treatments in each region revealed that vegetative biomass decreased in Zermatt under lowered soil moisture $(P=0.003)$, while it was not significantly affected in Davos $(P=0.93$; Fig. 3$)$. 
Fig. 1 Flowering phenology of six alpine populations of Anthyllis vulneraria in the common garden of the Botanical Institute in Basel in the two soil moisture treatments. Open symbols represent populations from Davos (Schiahorn, Casanna, Monstein), and closed symbols represent populations from Zermatt (Findelgletscher, Findelwald, Stafelalp). Error bars denote one standard error of the mean based on individual variation within population
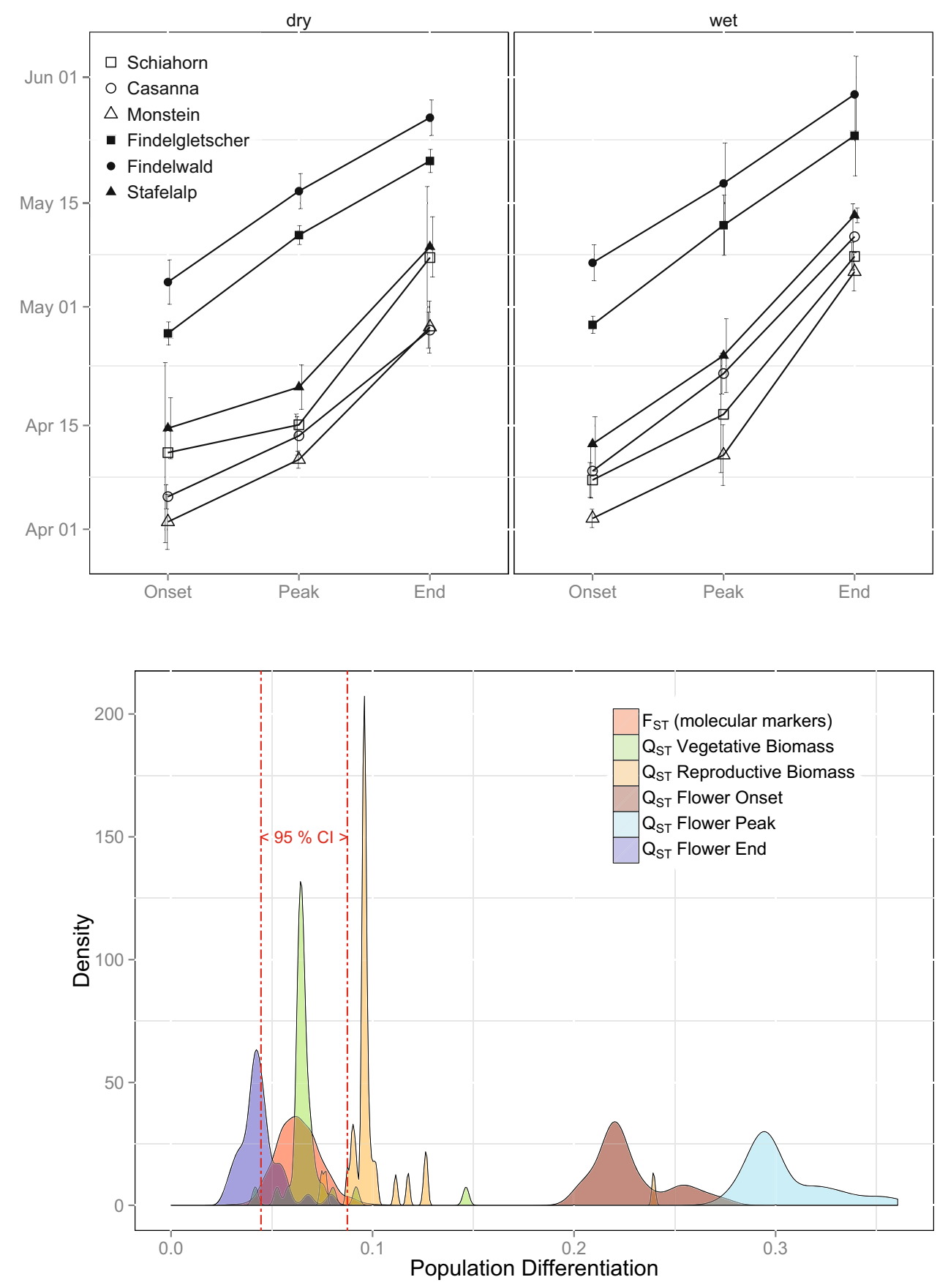

Fig. 2 Probability density distributions of $F_{\mathrm{ST}}$ and $Q_{\mathrm{ST}}$ 's for biomass and phenological traits. $10^{3}$ replicate values of $F_{\text {ST }}$ were generated by a nonparametric bootstrap. $F_{\mathrm{ST}}$ is based on microsatellites. Distributions of $Q_{\mathrm{ST}}$ 's for this plot consist of only 36 replicates per trait, which were generated by jackknifing over seed families. Vertical lines indicate the $95 \% \mathrm{CI}$ of the estimate of $F_{\mathrm{ST}} .95 \%$ CI of $Q_{\mathrm{ST}}$ 's of onset and peak of flowering do not overlap with the $95 \% \mathrm{CI}$ of the estimate of $F_{\mathrm{ST}}$ and therefore reveal a signature of past selection
Concerning reproductive biomass, contrasts of the treatments in each region revealed that both the Davos and Zermatt regions were significantly affected by lowered soil moisture $(P=0.04$; resp. $P<0.01)$, but the Zermatt region more strongly so. However, Fig. 3 suggests the region $\mathrm{x}$ treatment for reproductive biomass was largely driven by the two geographically adjacent populations of Findelgletscher and Findelwald, which responded with a strong decrease in reproductive biomass to the drought treatment. The third population from Zermatt (Stafelalp) reacted very similarly to the Davos populations with a small decrease in reproductive biomass (Fig. 3). Overall, the population-level decrease in reproductive biomass in response to drought was proportional to the mean reproductive biomass across both treatments (Pearson's product moment, $t=4.81, d f=4$, $P<0.01)$. There was no correlation of reproductive allocation with vegetative biomass across all populations at the level of seed family (Pearson's product moment, $t=1.75$, $d f=34, P>0.09$ ), and therefore no indication of a tradeoff between reproductive and vegetative biomass in the 

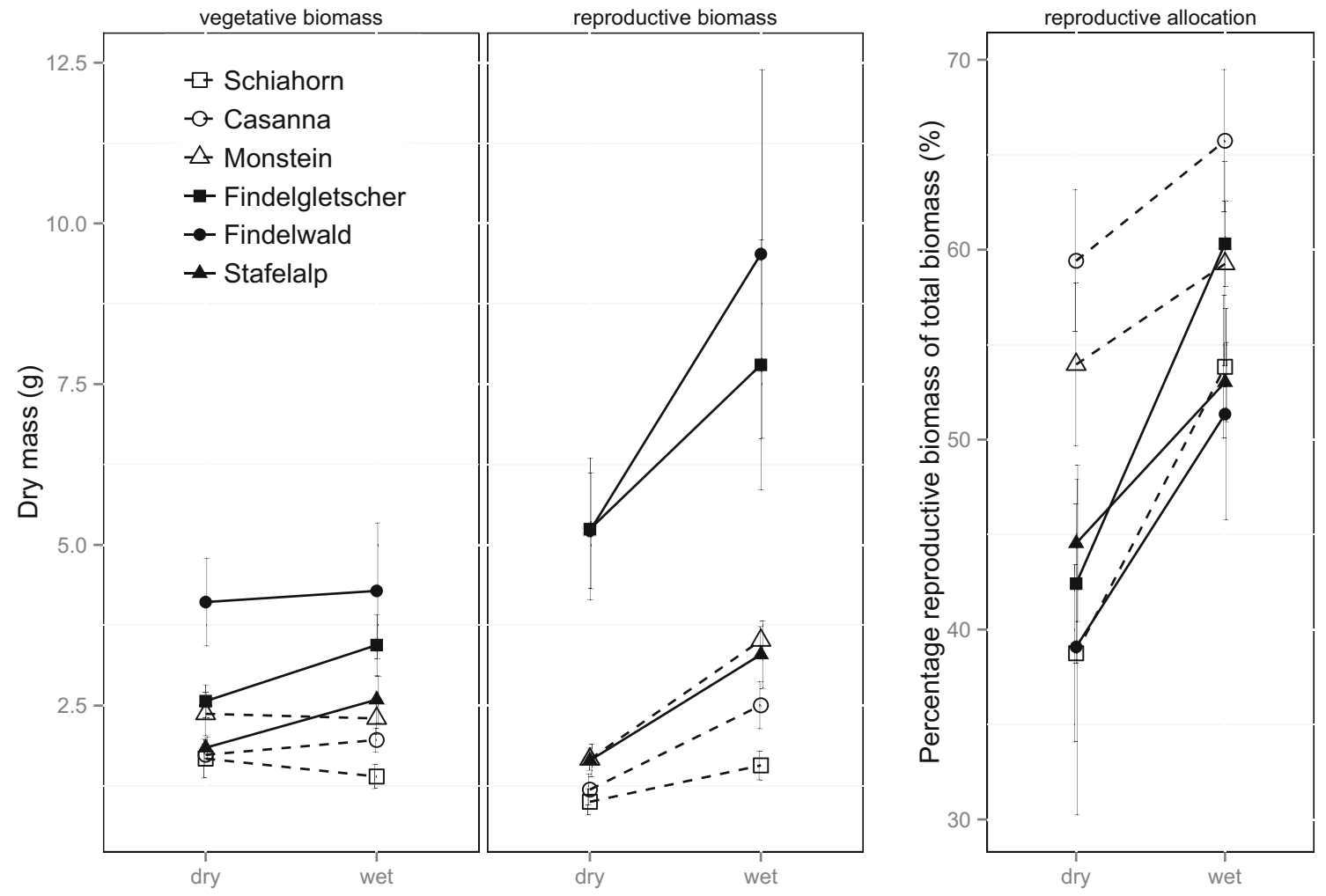

Fig. 3 Reaction norms of vegetative and reproductive aboveground biomass in response to two soil moisture treatments of six alpine populations of Anthyllis vulneraria in the common garden in Basel. Open symbols and dashed lines represent populations from Davos

studied populations. No significant interactions of treatment with population or seed family were found.

Reduced soil moisture treatment had no consistent effect on the onset of flowering, but significantly advanced peak flowering and end of flowering of all populations by an average of 3 and 6 days, respectively. No significant interactions of treatment with population or seed family were found.

\section{Discussion}

The current study demonstrates considerable variation in reproductive phenology and aboveground biomass among six alpine populations of Anthyllis vulneraria sampled in two contrasting regions. $Q_{\mathrm{ST}}-F_{\mathrm{ST}}$ comparisons suggest that divergent selection likely caused population genetic differentiation in onset and peak of flowering but not in biomass. Substantial amounts of variation in all measured traits are explained by family membership, indicating within-population genetic variation and sustained potential for future evolution. Soil moisture treatment had a significant effect on biomass traits, and resulted in a small but statistically significant forward shift of peak and end of flowering. No
(Schiahorn, Casanna, Monstein), and closed symbols and solid lines represent populations from Zermatt (Findelgletscher, Findelwald, Stafelalp). Error bars denote one standard error of the mean based on individual variation within population

genetic variation in plastic responses to soil moisture was found within populations, neither for flowering phenology nor for biomass traits. Moreover, populations within each region did also not differ in their plastic response to drought, but across regions populations responded differently in vegetative biomass.

\section{Variation in biomass allocation}

There is good evidence that reproductive allocation increases along elevation (Fabbro and Körner 2004; Zhu et al. 2010). Since our populations are not spread along elevation very far and since we study only three populations per region, it is not surprising that we do not find differentiation beyond the neutral expectation in reproductive allocation across such short geographic distances as indicated by $Q_{\mathrm{ST}}-$ $F_{\text {ST }}$ comparison.

Both vegetative and reproductive biomass were plastic in response to soil moisture availability suggesting that summer precipitation plays a role for growth and reproduction of alpine Anthyllis vulneraria. Drought stress in the alpine life zone is a phenomenon mostly reserved to special microhabitats such as extremely shallow or exposed substrates (Neuner et al. 1999), and tolerance to desiccation is often 
high (Körner 2003). However, reduced soil moisture—even if it does not cause problems with maintaining turgorfrequently leads to nutrient limitation and therefore reduced growth (Körner 2003). Interestingly, reduced soil moisture did not have a negative effect on vegetative biomass for populations from Davos. Previous results also show no effect or a slightly positive effect of drought for alpine grassland sites receiving high annual precipitation (Gilgen and Buchmann 2009). Drought stress therefore seems to be avoided in the Davos populations through slow growth resulting in lower total leaf surface area and consequently in lower transpiration. Whether this pattern is a genetic adaptation driven by regional differences in precipitation should be further investigated with a larger number of populations and measurements of in situ water availability. Statistical models and graphical inspection also showed that there is no significant within-population genetic variation in phenotypic plasticity in response to soil moisture, meaning that all seed families within a population responded similarly to soil moisture change. This is in line with the absence of divergent selection across populations as found in the $Q_{\mathrm{ST}}-F_{\mathrm{ST}}$ comparison, because environmental heterogeneity in water limitation and associated divergent selection are predicted to preserve genetic variation in plasticity (Via and Lande 1985). Although stabilizing selection across populations on trait means was not indicated by the $Q_{\mathrm{ST}}-F_{\mathrm{ST}}$ comparison for biomass traits, stabilizing selection on reaction norms rather than on trait means might still be present and explain the absence of genetic variation in plasticity within populations.

\section{Variation in reproductive phenology}

Populations of Anthyllis vulneraria are differentiated in their reproductive phenology at all spatial scales from more than a $100 \mathrm{~km}$ to a few $\mathrm{km}$. Snowmelt date was drastically advanced in our common garden compared to the natural sites because the garden is situated at much lower elevation. Genetic differences in photoperiodic sensitivity between populations, i.e. $G \times E$ in photoperiodic control, might therefore have become visible in our garden (Pigliucci 2003). Likewise $G \times E$ in vernalisation requirement might also contribute to the variation that was found in the common garden (Mendez-Vigo et al. 2013). Yet the strong forward shift in the phenology of all populations compared to the natural sites suggests strong insensitivity to photoperiod of all populations. Furthermore, we observed comparable differences in flowering time in an accompanying experiment with transplantations into the original field sites (Halil Kesselring, personal observation). Therefore, it is more plausible, as the $Q_{\mathrm{ST}}-F_{\mathrm{ST}}$ comparison suggests, that heterogeneous selection on onset and peak of flowering is the reason for the within-region population differentiation in these traits. Because a total of only six populations and a regional subdivision were used in our study, it is not feasible to correlate flowering dates with environmental variables at the sites of origin. Such correlations could strengthen the case for past and current adaptive evolution of flowering time and inform about selective agents. An emerging key environmental determinant of plant distributions in alpine habitats is spring frost (Bannister et al. 2005; Ladinig et al. 2013; Lenz et al. 2013; Briceño et al. 2014; Wheeler et al. 2014). The likelihood of spring frost at any elevation is largely determined by the date of snowmelt, which in turn is a function of winter precipitation, and topography. A thick snow cover in spring buffers temperature fluctuations and protects critical plant tissues from freezing damage due to very low temperatures. Reproductive structures of flowering plants are highly frost-susceptible and much less frost-tolerant than vegetative plant tissues (Neuner et al. 2013). Consequently, the timing of reproduction is expected to evolve so as to avoid periods with a high likelihood of frost. Sites with little snow accumulation during winter and relatively early snowmelt experience spring frost more commonly and should extend the pre-flowering duration. Similarly to spring frost, the emergence of pollinating insects of Anthyllis vulneraria can also potentially select for corresponding peak flowering times. As the activity of pollinating insects is strongly temperature-dependent, differences in elevation and exposition among populations could lead to divergent selection through pollinators (Kudo 1996). Flowering phenology is a trait particularly likely to be differentiated even over short geographical distances, because it is also a mechanism to reduce gene flow via pollen movement between individuals flowering at different times (Linhart and Grant 1996). There is a shortage of studies investigating whether populations of alpine plants at similar elevations experience divergent selection on flowering time by the local environments, and future studies should test the link between snowmelt date, pollinator abundances, and flowering time.

The observed advances of peak and end of flowering in response to decreased soil moisture availability—although mild as they were-are in keeping with a strategy of quick reproduction under stressful conditions. This is a previously observed reaction of short-lived plants on short as well as evolutionary timescales (Dunne et al. 2003; Franks 2011). Peak flowering date per seed family was not a function of the reproductive biomass (ANCOVA, $F=1.25, p=0.27$ ). Hence, it is unlikely that the advanced dates of peak and end of flowering are merely the result of decreased biomass. Likewise, the time between re-establishment of the treatment in the second growing season to onset of flowering was not correlated to plasticity in flowering onset either, meaning that later-flowering populations were not more plastic. Therefore, the absence of a plastic response of flowering 
onset to soil moisture is unlikely the result of the suspension of the treatment during winter. Advanced peak and end of flowering therefore potentially reflect an adaptive drought escape strategy in Anthyllis vulneraria. No variation in the response of the flowering phenology to soil moisture availability was indicated by statistical analyses, neither at the among-population nor at the within-population level (Table 3). As theory predicts that genetic variation in plasticity should be preserved under conditions of heterogeneous selection (Via and Lande 1985), one might conclude from these results that variability in soil moisture leading to heterogeneous selection on flowering phenology does not exist at the scale at which populations were sampled in this experiment ( $<20 \mathrm{~km}$ within regions). Alternatively, evolutionary constraints or stabilizing selection on reaction norms may be present.

\section{Accuracy of $Q_{\mathrm{ST}}$ and $F_{\mathrm{ST}}$ estimation}

The method of comparing $Q_{\mathrm{ST}}$ to the neutral expectation using $F_{\mathrm{ST}}$ has been scrutinized, because both indices are not without problems (e.g. McKay and Latta 2002; O'Hara and Merilä 2005). The accuracy of the estimation of $Q_{\mathrm{ST}}$ depends on how well we can separate additive genetic variance $\left(V_{\mathrm{A}}\right)$ within and between populations from environmental effects, maternal effects, and non-additive genetic effects such as dominance. Since we have largely reduced environmental variation by raising all plants in a common garden and controlling for soil moisture availability to our best ability, direct environmental effects should be minimal in our study (Leinonen et al. 2008). Indirect environmental variation can still occur through maternal effects in our design as we used maternal halfsibs to estimate $V_{\mathrm{A}}$. However, maternal effects in plants have so far almost exclusively been found to affect only early life history stages and to diminish over time (Bischoff and Müller-Schärer 2010 and references therein). As our plants were in the second growing season when traits were measured, maternal effects might not have had a considerable effect on the outcome. Furthermore, we have included early leaf size as covariate in the analyses, a method commonly used to control for maternal effects (Scheepens and Stöcklin 2013). We used the phenotypic resemblance of open-pollinated half-sibs to assess $V_{\mathrm{A}}$, a method that confounds additive with non-additive genetic effects such as dominance. However, non-additive effects always cause a downward bias in estimating $Q_{\mathrm{ST}}$ (Lynch and Walsh 1998), and therefore render tests of $Q_{\mathrm{ST}}>F_{\mathrm{ST}}$ conservative. As we found no $Q_{\mathrm{ST}}$ smaller than $F_{\mathrm{ST}}$, this bias is unlikely to affect our conclusions. Finally, $F_{\mathrm{ST}}$ has been hotly debated as an accurate measure of neutral population differentiation and the molecular markers used to assess it are criticised (e.g. Hedrick 2005; Jost 2008). In this study, we used microsatellites, which are notorious for having a high mutation rate resulting in lower estimates of $F_{\text {ST. }}$. Indeed, Jost's estimate of differentiation was more than twice as big as $F_{\mathrm{ST}}$. However, since this difference is still mild compared to many previous microsatellite studies, and since far less than one private allele per locus and population was found (results not shown), we suspect that our microsatellites do not have an exceedingly high mutation rate and are therefore suitable for comparisons of $Q_{\mathrm{ST}}$ with $F_{\mathrm{ST}}$ (Edelaar and Björklund 2011). Furthermore, Jost's estimate of differentiation was still smaller than both $Q_{\mathrm{ST}}$ 's concluded to be significantly larger than $F_{\mathrm{ST}}$. Consequently, if our $F_{\text {ST }}$ falsely underestimates population differentiation at neutral marker sites, then this would mostly affect our conclusions that none of the traits is under stabilizing selection across populations. In summary, we are confident in the accuracy of the results with the exception of underestimating stabilizing selection across the Alps in plant size. Nonetheless, we caution the reader against taking $Q_{\mathrm{ST}}-F_{\mathrm{ST}}$ comparisons as definitive proof for the presence or absence of selection.

\section{Conclusion}

Our results suggest that the timing of onset and peak of flowering has been under divergent selection among populations of alpine Anthyllis vulneraria. Populations were differentiated in onset and peak of flowering up to 5 weeks across regions and more than 2 weeks within regions when grown in the common garden. Analyses suggest that differentiation resulting from selection occurs even at spatial scales $<20 \mathrm{~km}$ and we hypothesize it is the result of temperature differences at the population sites resulting in divergent snowmelt and pollinator conditions. We found ample genetic variation within populations for all traits, supporting the idea that future adaptations in flowering phenology and reproductive allocation to novel conditions are possible. However, genetic variation in phenotypic plasticity in response to soil moisture availability was absent for all traits studied. This indicates either the absence of significant heterogeneity in soil moisture across populations, or stabilizing selection on reaction norms across populations, or in the case of flowering phenology might be due to the low overall plasticity in flowering phenology in response to soil moisture.

Acknowledgments The work was supported financially by the Swiss National Science Foundation Grant No. 3100A-135611 to JS, and the Freiwillige Akademische Gesellschaft Basel and the Basler 
Stiftung für biologische Forschung to HK. Three anonymous reviewers have helped to improve the manuscript.

\section{Compliance with ethical standards}

Conflict of interest The authors declare that they have no conflict of interest. No animals were used in this study.

\section{References}

Bannister P et al (2005) Will loss of snow cover during climatic warming expose New Zealand alpine plants to increased frost damage? Oecologia 144:245-256

Bergman P, Molau U, Holmgren B (1996) Micrometeorological impacts on insect activity and plant reproductive success in an alpine environment, Swedish Lapland. Arct Alp Res 28:196-202

Bischoff A, Müller-Schärer H (2010) Testing population differentiation in plant species-how important are environmental maternal effects. Oikos 119:445-454

Bradshaw AD (1965) Evolutionary significance of phenotypic plasticity in plants. In: Caspari EW, Thoday JM (eds) Advances in genetics, vol 13. Academic Press, New York, pp 115-155

Briceño VF, Harris-Pascal D, Nicotra AB, Williams E, Ball MC (2014) Variation in snow cover drives differences in frost resistance in seedlings of the alpine herb Aciphylla glacialis. Environ Exp Bot 106:174-181

Caruso CM (2006) Plasticity of inflorescence traits in Lobelia siphilitica (Lobeliaceae) in response to soil water availability. Am J Bot 93:531-538

Chapuis MP, Estoup A (2007) Microsatellite null alleles and estimation of population differentiation. Mol Biol Evol 24:621-631

David P, Pujol B, Viard F, Castella V, Goudet J (2007) Reliable selfing rate estimates from imperfect population genetic data. Mol Ecol 16:2474-2487

Dunne JA, Harte J, Taylor KJ (2003) Subalpine meadow flowering phenology responses to climate change: integrating experimental and gradient methods. Ecol Monogr 73:69-86

Edelaar P, Björklund M (2011) If $F_{\mathrm{ST}}$ does not measure neutral genetic differentiation, then comparing it with $Q_{\mathrm{ST}}$ is misleading. Or is it? Mol Ecol 20:1805-1812

Fabbro T, Körner C (2004) Altitudinal differences in flower traits and reproductive allocation. Flora Morphol Distrib Funct Ecol Plants 199:70-81

Franks SJ (2011) Plasticity and evolution in drought avoidance and escape in the annual plant Brassica rapa. New Phytol 190:249-257

Frei ER, Hahn T, Ghazoul J, Pluess AR (2014) Divergent selection in low and high elevation populations of a perennial herb in the Swiss Alps. Alp Bot 124:131-142

Galen C, Sherry RA, Carroll AB (1999) Are flowers physiological sinks or faucets? Costs and correlates of water use by flowers of Polemonium viscosum. Oecologia 118:461-470

Gilgen AK, Buchmann N (2009) Response of temperate grasslands at different altitudes to simulated summer drought differed but scaled with annual precipitation. Biogeosciences 6:2525-2539

Guillaume F, Rougemont J (2006) Nemo: an evolutionary and population genetics programming framework. Bioinformatics 22:2556-2557

Hall MC, Willis JH (2006) Divergent selection on flowering time contributes to local adaptation in Mimulus guttatus populations. Evolution 60:2466-2477
Hedrick PW (2005) A standardized genetic differentiation measure. Evolution 59:1633-1638

Hegi G (1975) Illustrierte Flora von Mitteleuropa. vol 4. Dicotyledones, 3rd edn. Verlag, Berlin

Hülber K, Gottfried M, Pauli H, Reiter K, Winkler M, Grabherr G (2006) Phenological responses of snowbed species to snow removal dates in the central Alps: implications for climate warming. Arct Antarct Alp Res 38:99-103

Hülber K, Winkler M, Grabherr G (2010) Intraseasonal climate and habitat-specific variability controls the flowering phenology of high alpine plant species. Funct Ecol 24:245-252

Jost $L$ (2008) $\mathrm{G}_{\mathrm{ST}}$ and its relatives do not measure differentiation. Mol Ecol 17:4015-4026

Keller F, Körner C (2003) The role of photoperiodism in alpine plant development. Arct Antarct Alp Res 35:361-368

Kesselring H, Hamann E, Stöcklin J, Armbruster GFJ (2013) New microsatellite markers for Anthyllis vulneraria (Fabaceae), analyzed with Spreadex gel electrophoresis. Appl Plant Sci $1: 1300054$

Körner C (2003) Alpine plant life: functional plant ecology of high mountain ecosystems. Springer, Berlin

Köster E, Bitocchi E, Papa R, Pihu S (2008) Genetic structure of the Anthyllis vulneraria L. s. 1. species complex in Estonia based on AFLPs. Cent Eur J Biol 3:442-450

Kudo G (1996) Effects of snowmelt timing on reproductive phenology and pollination process of alpine plants, vol Special Issue No. 51. Mem Natl Inst Polar Res, Tokyo

Kuznetsova A, Brockhoff PB, Christensen RHB (2013) lmerTest: tests for random and fixed effects for linear mixed effect models (lmer objects of lme4 package). R-Version: 1.1-0. http://cran.rproject.org/web/packages/lmerTest/index.html

Ladinig U, Hacker J, Neuner G, Wagner J (2013) How endangered is sexual reproduction of high-mountain plants by summer frosts? Frost resistance, frequency of frost events and risk assessment. Oecologia 171:743-760

Lambrecht SC (2013) Floral water costs and size variation in the highly selfing Leptosiphon bicolor (Polemoniaceae). Int J Plant Sci 174:74-84

Lauber K, Wagner G, Gygax A (2012) Flora Helvetica, 5th edn. Verlag, Tokyo

Leimu R, Fischer M (2008) A meta-analysis of local adaptation in plants. PLoS One 3:e4010

Leinonen T, O’Hara RB, Cano JM, Merilä J (2008) Comparative studies of quantitative trait and neutral marker divergence: a meta-analysis. J Evol Biol 21:1-17

Lenz A, Hoch G, Vitasse Y, Körner C (2013) European deciduous trees exhibit similar safety margins against damage by spring freeze events along elevational gradients. New Phytol 200:1166-1175

Linhart YB, Grant MC (1996) Evolutionary significance of local genetic differentiation in plants. Annu Rev Ecol Syst 27:237-277

Lynch M, Walsh B (1998) Genetics and analysis of quantitative traits. Sinauer Associates, Sunderland

Mal TK, Lovett-Doust J (2005) Phenotypic plasticity in vegetative and reproductive traits in an invasive weed, Lythrum salicaria (Lythraceae), in response to soil moisture. Am J Bot 92:819-825

McKay JK, Latta RG (2002) Adaptive population divergence: markers, QTL and traits. Trends Ecol Evol 17:285-291

Méndez-Vigo B, Gomaa NH, Alonso-Blanco C, Picó FX (2013) Among- and within-population variation in flowering time of Iberian Arabidopsis thaliana estimated in field and glasshouse conditions. New Phytol 197:1332-1343

Müller H (1881) Alpenblumen, ihre Befruchtung durch Insekten und ihre Anpassungen an dieselben. W. Engelmann, Switzerland 
Nanni L, Ferradini N, Taffetani F, Papa R (2004) Molecular phylogeny of Anthyllis spp. Plant Biol 6:454-464

Navarro L (1999) Allocation of reproductive resources within inflorescences of Anthyllis vulneraria subsp. vulgaris (Fabaceae). In: Hemsley AR, Kurmann MH (eds) The evolution of plant architecture, vol 1. Royal Botanic Gardens, Kew, pp 323-330

Neuner G, Braun V, Buchner O, Taschler D (1999) Leaf rosette closure in the alpine rock species Saxifraga paniculata Mill.: significance for survival of drought and heat under high irradiation. Plant Cell Environ 22:1539-1548

Neuner G, Erler A, Ladinig U, Hacker J, Wagner J (2013) Frost resistance of reproductive tissues during various stages of development in high mountain plants. Physiol Plant 147:88-100

O’Hara RB, Merilä J (2005) Bias and precision in Qst estimates: problems and some solutions. Genetics 171:1331-1339

Ozenda P (1985) La végétation de la chaîne alpine. Masson

Pannell JR, Labouche AM (2013) The incidence and selection of multiple mating in plants. Phil Trans R Soc B Biol Sci 368:20120051

Peakall R, Smouse PE (2006) GENALEX 6: genetic analysis in Excel. Population genetic software for teaching and research. Mol Ecol Notes 6:288-295

Pigliucci M (2003) Selection in a model system: ecological genetics of flowering time in Arabidopsis thaliana. Ecology $84: 1700-1712$

R Development Core Team (2008) R: a language and environment for statistical computing. $\mathrm{R}$ foundation for statistical computing, Vienna

Rathcke B, Lacey EP (1985) Phenological patterns of terrestrial plants. Annu Rev Ecol Syst 16:179-214

Scheepens JF, Stöcklin J (2013) Flowering phenology and reproductive fitness along a mountain slope: maladaptive responses to transplantation to a warmer climate in Campanula thyrsoides. Oecologia 171:679-691
Scheepens JF, Kuss P, Stöcklin J (2011) Differentiation in morphology and flowering phenology between two Campanula thyrsoides L. subspecies. Alp Bot 121:37-47

Scherrer D, Körner C (2010) Infra-red thermometry of alpine landscapes challenges climatic warming projections. Glob Chang Biol 16:2602-2613

Schluter D (2009) Evidence for ecological speciation and its alternative. Science 323:737-741

Schroeter C (1923) Das Pflanzenleben der Alpen. Teile 1-4. A. Raustein, Zurich, Switzerland

Spitze K (1993) Population structure in Daphnia obtusa: quantitative genetic and allozymic variation. Genetics 135:367-374

Sultan SE, Spencer HG (2002) Metapopulation structure favors plasticity over local adaptation. Am Nat 160:271-283

Via S, Lande R (1985) Genotype-environment interaction and the evolution of phenotypic plasticity. Evolution 39:505-522

Weir BS, Cockerham CC (1984) Estimating F-statistics for the analysis of population structure. Evolution 38:1358-1370

Wheeler JA, Hoch G, Cortés AJ, Sedlacek J, Wipf S, Rixen C (2014) Increased spring freezing vulnerability for alpine shrubs under early snowmelt. Oecologia 175:219-229

Whitlock MC, Guillaume F (2009) Testing for spatially divergent selection: comparing $Q_{\mathrm{ST}}$ to $F_{\mathrm{ST}}$. Genetics 183:1055-1063

Wright S (1931) Evolution in mendelian populations. Genetics 16:97-159

Zhu Y, Siegwolf RTW, Durka W, Koerner C (2010) Phylogenetically balanced evidence for structural and carbon isotope responses in plants along elevational gradients. Oecologia 162:853-863

Zimmermann NE, Kienast F (1999) Predictive mapping of alpine grasslands in Switzerland: species versus community approach. J Veg Sci 10:469-482 